\title{
Autoetnografía y reflexiones en la pandemia por COVID-19
}

\section{Autoethnography and reflections on the COVID-19 pandemic Antropologia cultural e reflexões na pandemia pela COVID-19}

\author{
Edwin Darío Archila-Hernández ${ }^{1^{*}}$ \\ Oscar Javier Vergara-Escobar ${ }^{2}$
}

\section{Resumen}

La pandemia de la COVID 19 es un problema mundial que no solo ha causado muertes y enfermos, sino que ha afectado la vida de los trabajadores de la salud. Para este artículo se desarrolla un relato a través de la autoetnografía, lo que permite hacer un acercamiento a los cambios generados dentro de una institución en salud a causa de esta situación, permitiendo trasladar las experiencias de la práctica a la teoría y analizar situaciones de lo sucedido en la atención de pacientes infectados. El objetivo es describir algunas vivencias de profesionales y auxiliares de la enfermería sobre la atención de pacientes con COVID-19 en un hospital universitario de Colombia y lo que implica el cuidado de la enfermería en una pandemia, usando los metaparadigmas y evidenciando el impacto de todos estos cambios en las personas y en la sociedad en general. Conclusión: los profesionales de la enfermería siempre estarán en primera línea, brindando las mejores experiencias de cuidado a las personas, sus familias y además acompañándolos en los procesos de nacer, crecer, vivir y morir. Aunque exista tecnología, pandemias, problemas sociales en el mundo, la enfermería seguirá participando, expresando sus sentires y trascendiendo en la vida de las personas con los actos de cuidado humano.

Palabras clave: Infecciones por coronavirus; enfermería; narrativa personal; atención de enfermería.

\begin{abstract}
The COVID 19 pandemic is a global issue that not only has caused deaths and contagion, but also has affected the life of healthcare workers. For this article a narrative is performed through autoethnography, approaching the changes within a health institution generated by this situation, allowing to transfer the practice experiences to the theory and analyze situations during the assistance of infected patients. The objective is to describe some of the experiences from the professionals and nursing assistants about the assistance of patients with COVID-19 in a university hospital in Colombia and what implies the nursing care implies during a pandemic, using the metaparadigms and evidencing the impact of all these changes in people and society in general. Conclusion: The nursing professionals will always be on the first line, providing the best care experience for people, their families as well as accompanying them during the processes of birth, growth, life and death. Although there are technologies, pandemics, social issues around the globe, nursing will keep participating, expressing its feelings and transcending in the lives of people as actors of human care
\end{abstract}

Keywords: Coronavirus infections; nursing; personal narrative; nursing care

\begin{abstract}
Autor de correspondencia*
1* Enfermero, especialista en Docencia Universitaria, Maestrando en Ciencias Básicas Biomédicas, referente de educación y calidad para la subdirección de enfermería en el Hospital Universitario de la Samaritana. Integrante del grupo de investigación Enfermería-HUS. Bogotá, Colombia. Correo: edarah-96@ $\underline{\text { hotmail.com (D) 0000-0002-8633-8031 }}$

2 Enfermero, especialista en Promoción de la Salud y Desarrollo Humano, Magister y Doctor en Enfermería, integrante del grupo de Investigación GRINENC Hospital Militar Central. Profesor Escuela de Enfermería, Fundación Universitaria Juan N Corpas. Bogotá, Grupo de Investigación CUIDARTE. Bogotá, Colombia: Correo: oscar.vergara@juanncorpas.edu.co (i) 0000-0003$\underline{3158-9017}$
\end{abstract}

Recibido: 11 febrero 2021

Aprobado: 20 junio 2021

\section{Para citar este artículo}

Archila-Hernández ED, Vergara-Escobar OJ. Autoetnografía y reflexiones en la pandemia por COVID-19. Rev. cienc. cuidad. 2021; 18(3):100-110. https://doi. org/10.22463/17949831.2853

(C) Universidad Francisco de Paula Santander. Este es un artículo bajo la licencia CC-BY-NC-ND 


\section{Scientific Journal of Nursing}

\section{Resumo}

A pandemia pela COVID-19 é um problema mundial que não só tem gerado morte e doença, além disso tem afetado a vida dos trabalhadores do setor saúde. Para esse artigo desenvolveu-se um relato através de antropologia cultural, permitindo fazer uma aproximação às mudanças geradas no interior da instituição de saúde como consequência dessa situação, permitindo trasladar a experiência da prática à teoria e analisar o acontecido no atendimento aos sujeitos infetados. O objetivo é descrever algumas vivências dos profissionais e a equipe técnica de enfermagem sobre o atendimento de pacientes com a COVID-19 num hospital escola de Colômbia e as suas implicações no cuidado de enfermagem numa pandemia, usando os metaparadigmas e evidenciando o impacto de todas essas mudanças nas pessoas e na sociedade no geral. Conclusão: os profissionais de enfermagem sempre estarão na primeira linha, prestando as melhores experiências de cuidado às pessoas, as suas famílias e além disso, acompanhando os processos de nascer, crescer, viver e morrer. Embora exista tecnologia, pandemias e problemas sociais no mundo, a enfermagem continuara participando, expressando os seus sentimentos e transcendendo na vida das pessoas com os atos de cuidado humano.

Palavras-chave: Infecções por coronavirus; enfermagem; narrativa pessoal; cuidados de enfermagem.

\section{Introducción}

A finales de diciembre del año 2019 en China, en Wuhan, provincia de Hubei, se empezaron a detectar pacientes con signos y síntomas característicos de una neumonía de origen desconocido. Los primeros síntomas descritos fueron: fiebre, tos seca, fatiga y síntomas gastrointestinales ocasionales (1). Después de realizar todo el seguimiento epidemiológico y ver el aumento progresivo de casos, Wuhan decidió declarar la emergencia sanitaria y poco tiempo después la Organización Mundial de la Salud (OMS) hizo el anuncio de una nueva pandemia causada por un virus perteneciente a la familia de "Los coronavirus", el cual lleva al desarrollo del síndrome respiratorio agudo severo. Los coronavirus son virus de Ácido Ribonucleico (ARN) de cadena sencilla de sentido positivo, con envoltura; cuenta con 5 proteínas estructurales y 16 proteínas no estructurales con las cuales ingresa a las células y se replican para causar la infección en el huésped (2).

Desde su detección inicial hasta febrero del año 2021 se habían confirmado más de 105.712.807 casos de personas infectadas en todo el mundo y más 2.307.047 muertes; Estados Unidos encabezaba la cifra de pacientes infectados con más de 26.901.496 de casos diagnosticados; India con más de 10.814.304 de casos, era el segundo país con más contagiados, seguido de Brasil con más de 9.447.165 casos y en cuarto lugar, se encontraba el Reino Unido, con más de 3.941.248 casos (3). Los cuatro países han adelantado por millones de casos a China, el epicentro original de la pandemia con algo más de 100.337 casos diagnosticados. En Colombia para esta fecha 2021, se habían diagnosticado más de 2.151.207 casos con más de 55.693 desenlaces fatales después de 11 meses de detectado el primer caso (4), datos que van cambiando por las dinámicas de transmisión del virus asociadas a la aparición de nuevas variantes.

A esta situación se vienen sumando todos los problemas psicológicos que se pueden desencadenar en los profesionales de salud, debido a su participación directa en actividades de diagnóstico con la toma de la muestra, el tratamiento y la atención de pacientes con COVID-19. Estas actividades los afectan al ser posibles víctimas de contagio y adicionalmente desarrollan angustia psicológica, incertidumbre, agotamiento físico y otros síntomas que afectan su salud mental. Además, un número cada vez mayor de casos confirmados y sospechosos, con una alta carga de trabajo, el agotamiento generado por el uso de los elementos de protección personal (5), la muerte de algunos colegas y de los mismos pacientes, hacen que la carga psicológica y emocional tenga un impacto negativo en la salud mental de los profesionales de la salud, motivos que me llevan a hacer una breve descripción de mis vivencias y de algunos de mis compañeros en la atención a pacientes con COVID-19.

\section{Metodología}

Este trabajo utiliza la autoetnografía como herramienta 
socio humana para explorar las experiencias de un profesional de la enfermería en el ámbito hospitalario y las acciones realizadas en el escenario de la pandemia por el COVID-19.

A partir de los años noventa Carolyn Ellis y Arthur Bochner, se consideran como los fundadores y activos promotores de la autoetnografía entendida como un "método de investigación" junto a Laurel Richardson (2003) otra de las figuras más conocidas, quien utiliza "la escritura como método de investigación". Estos autores plantean que en esta vertiente se "explora el uso de la primera persona al escribir, la apropiación de modos literarios con fines utilitarios y las complicaciones de estar ubicado dentro de lo que uno está estudiando" (6).

Conviene subrayar, que como método, la autoetnografía combina características de la autobiografía y la etnografía. Al escribir una autobiografía, un autor escribe sobre experiencias pasadas que fueron muy significativas y puede enriquecer sus datos al entrevistar a otros, así como consultar textos, apoyarse de las fotografías y grabaciones para ayudar a recordar (7).

Frecuentemente, los autobiógrafos escriben sobre momentos que recuerdan que tuvieron un impacto significativo, una situación en concreto durante la vida (8-10), o en momentos de crisis existencial, como lo que ha ocurrido durante la pandemia, que obligó a muchas personas y grupos sociales a poner atención y analizar las experiencias que tuvieron un impacto en las dinámicas de la vida (11). Estos sucesos constituyen un fenómeno íntimo que una persona puede considerar como una experiencia transformadora, mientras que para otra tal vez no significa nada; es decir, que se observan diferentes maneras en que podrían manejarse las "situaciones intensas" y los "efectos que perduran como los recuerdos, las imágenes y los sentimientos por mucho tiempo después, sobre un evento significativo, que supone ha concluido".

Por otra parte, para Blanco la autoetnografía es un método de investigación cualitativa que permite desde su naturaleza identificar fenómenos propios que requieren ser descritos y por eso es imprescindible ubicarla como una estructura narrativa (que incluye una trama o el argumento del relato), lo que supone la utilización de "formatos narrativos" los cuales deben contar con características que le permitan referirse a una relato de manera breve, debido a las limitaciones de espacio, pero que además cuente con el encuadre teórico metodológico (12), usando las etapas de la investigación: recopilación, redacción de datos y análisis (13).
Se debe señalar que la autoetnografía se ubica en una perspectiva epistemológica que sostiene una vida individual, que da cuenta de los contextos en los que le toca vivir a esa persona, así como de las épocas históricas que recorre a lo largo de su existencia (12). Para Franco Ferrarotti con la autoetnografía "El individuo no totaliza una sociedad global directamente. Lo hace a través de la mediación de su contexto social inmediato y de los grupos limitados de los cuales forma parte [...]. De igual manera, la sociedad totaliza a cada individuo específico a través de las instituciones mediadoras..." (12).

Es necesario recalcar que las autoetnografías son altamente personalizadas, textos reveladores en los cuales los autores cuentan relatos sobre su propia experiencia vivida, relacionando lo personal, lo cultural y tienen una estructura narrativa (12); es decir, que incluye una trama o el argumento del relato. Por tanto se propone la construcción de un texto que permite narrar parte de los cambios en el cuidado de la enfermería en un hospital universitario, frente a la atención de pacientes con COVID-19. Este método es muy usado en las ciencias como la antropología, la sociología y la comunicación.

Recopilación: Los datos se tomaron de las experiencias de uno de los autores que labora en el contexto hospitalario de tercer nivel de atención en Colombia. Esta es una institución prestadora de servicios de salud, con acreditación institucional, ubicada en la ciudad de Bogotá; además es reconocida por ser una institución universitaria, que promueve la investigación y la formación de profesionales de la salud. La institución cuenta con 260 camas habilitadas y otras instalaciones, donde trabajan alrededor de 120 profesionales y 350 auxiliares de enfermería para atender a los pacientes que ingresan. Aunque las personas que tuvieron un mayor contacto con la atención de estos pacientes fueron los que se encontraban en los servicios denominados "áreas COVID-19" (UCI, Urgencias y hospitalización), las preocupaciones y sentimientos también fueron expresados por el personal que no se encontraba en estas áreas, quienes al estar en una institución de salud se sentían en riesgo.

De acuerdo con la población objeto de estudio, se realizó una observación sobre el actuar del personal de enfermería, sus emociones y sentimientos frente a la situación, de acuerdo a lo que ellos expresaban, sin necesidad de hacer preguntas al respecto; después se efectuó una auto-observación que se traduce en la percepción directa de pensamientos, emociones, impulsos y sensaciones para hacer ciertas reflexiones (14). Además, se utilizó un diario de campo que permitió 
recolectar notas de campo metodológicas y observacionales; las experiencias se recolectaron en un periodo de 10 meses.

Análisis: La experiencias fueron interpretadas por los autores de manera reflexiva, lo que permitió reconocer, revivir y retomar los momentos vividos y aquellos acontecimientos que cambiaron la vida del grupo, tanto en los aspectos laborales como en los personales para convertirlo en una experiencia transformadora, que se convirtió en lo que es hoy la forma de cuidado del paciente con COVID-19 y el actuar de los involucrados ante la pandemia (13).

\section{Redacción de datos}

Narrativa: Voces en silencio en tiempos de la pandemia por COVID-19

Voces en silencio en tiempos de la pandemia por $\mathrm{COV}$ ID-19 en los servicios de enfermería de un hospital de III nivel de atención en Colombia en donde se vienen presentado estas vivencias (...) que quiero transmitir con respeto y consciencia del sentir de mis compañeros de trabajo. Hablar del cuidado de la enfermería involucra a la persona, a su familia y el entorno, y esto no se puede olvidar cuando somos trabajadores de la salud y estamos "en primera línea" jasí lo dicen la gente de la calle, los medios de comunicación y hasta los colegas!, no sé hasta qué punto sí somos o no primera línea, por ello me tomo la tarea de escribir las experiencias y sentimientos que se viven en la atención de enfermería en pacientes con diagnóstico de COVID-19 $y$ en el resto de pacientes que no lo son y que pareciera que sus necesidades en salud han sido olvidadas y esto también tiene implicación en los sentimientos y temores de los que los estamos cuidando, porque como dijo uno de mis compañeros: "a esta altura ya todos los pacientes son sospechosos”.

Recordando un trabajo que adelantamos desde nuestro grupo de investigación (liderado por enfermeros), donde construimos un Modelo de Cuidado propio, allí se conciben las personas como eje central de los servicios, y no podemos dejar a un lado el cuidado de nuestros compañeros de trabajo, ya que ellos también hacen parte de esas personas que cuidamos. Esta situación me ayuda a repensar y preguntarme ¿cómo podemos auto ayudarnos en tiempos de COVID-19? Estas personas son hombres y mujeres que para este caso se formaron para cuidar a los otros y desde ese cuidado humano que propicia, realizar acciones e intervenciones propias o con ayuda de otros profesionales para resolver las necesidades de las personas que están cuidando, no deben alejarse del autocuidado para poder seguir adelante en el cuidado de enfermería en estos tiempos tan dificiles, asi mismo durante ese proceso aparecen sentimientos, emociones, sueños y miedos.

Expresiones de mis compañeros como: "A mí no me importa mucho que yo me infecte, me afectaría llevar el virus a mi casa y que mi familia se infecte", estas preocupaciones rodean todos los días a mis compañeros en el hospital y se ve reflejado en los silencios que caminan por los servicios, pero ¿quién se ha detenido a preguntarnos sobre esos pensamientos?. Desde mi cargo comprendi en esta pandemia que puedo ser un puente, faro para mis compañeros en las tinieblas y llegar a tener empatía, comprensión y sobre todo, respeto por sus sentimientos en el día a día. Estos sentires hacen que tengamos pensamientos de vulnerabilidad, incertidumbre, temor, soledad y desesperanza que recaen en manifestaciones de los compañeros en frases como: "”No sé si ya me infecte", "tengo miedo de esta situación", "Extraño a mi familia y hace tiempo que no los veo", "No puedo dormir, me despierto a media noche", "tengo pesadillas y sueño que me he infectado", "me tocó irme de la casa". Todo es una voz a gritos, que afecta el cuerpo, el alma y los sueños de cada uno de los enfermeros, auxiliares de enfermería, camilleros y demás miembros del equipo de salud. Es necesario recordar que no somos los únicos con miedo, en el mundo existen otros profesionales de la enfermería que ya han pasado por esta situación y también sienten lo mismo en este momento, como lo demuestran algunos estudios $(15,16)$.

Todo esto, evoca un recuerdo de una tarde cuando pasaba ronda en el servicio de urgencias y vi el primer signo de ansiedad en uno de mis compañeros, cuando se presentó un caso curioso que sucedió con un paciente que ingresó por un dolor abdominal, todo el grupo interdisciplinario le realizó la valoración y las intervenciones necesarias para aliviar el dolor y poder hacer un diagnóstico acertado e identificar el origen. Unas horas después alguien se dio cuenta que este paciente era altamente sospechoso para COVID-19 y cuando uno de los integrantes del grupo de salud se enteró, salió al pasillo del servicio a gritar ....iDonde están los trajes de protección!, ¿quién está a cargo del servicio?, ipóngase los trajes rápido!, una reacción que muestra desconocimiento, miedo y ponerse en riesgo ante una persona, que tal vez esté infectada y tener ese temor de que puedo adquirir la infección; pero más que juzgar esta conducta, quiero llevar a la reflexión de cómo también los trabajadores de la salud, nos sentimos vulnerables frente a una enfermedad incierta y poco conocida, esta reacción producto de este temor que tenemos a los inexplorado y más cuando viene acompañado de 
un posible desenlace fatal. Ante esta situación creo que la pandemia nos ha enseñado a ser prudentes, a leer más evidencias cientificas y sobre todo a educarnos, a la vez que surgen estudios sobre este virus de ARN.

Estas personas o mis compañeros y yo, necesitamos apoyo, escucha, comprensión, capacitación y sobretodo hacernos sentir humanos; quizás antes habiamos olvidado o no éramos conscientes que también tenemos la misma piel que cualquier otro ser vivo, y este mensaje quizás sea el más importante que quiero recordar en medio de esta pandemia, que día a día nos sorprende y nos convierte también en sujetos de cuidado y es que es necesario que dignifiquemos nuestra existencia en la vida con consciencia, propósito y sentido, sin pasar por encima del otro. Desde la enfermería se deben planear intervenciones, estrategias, programas, $y$ un plan de autocuidado para apoyarlos y apoyarnos, y que a través de éstos se puedan crear herramientas para poder avanzar a pesar de las circunstancias y desarrollar habilidades para la vida como la resiliencia, el empoderamiento, el autocuidado, la toma de decisiones y manejo de nuestras propias emociones para convivir y sobrellevar el efecto de esta pandemia. iSomos también una luz de esperanza, portadores de voces silenciadas y quizás recordados como una profesión digna de cuidar la vida humana! De todo esto hemos aprendido a adaptarnos al cambio, transformar la vida, los escenarios de la práctica, usando elementos de protección que ocultan un rostro (...) pero no la esencia del arte del cuidado; para unos ha sido más fácil que para otros, como dijo una persona "el virus no va a desaparecer, debemos aprender a convivir con él", entendiendo la frase tiene razón y debemos continuar con nuestras actividades de cuidado, aplicando el autocuidado con el uso de los elementos de protección, la limpieza y desinfección de nuestro entorno, "somos entonces los profesionales de la enfermería, sembradores de esperanza, iniciando con nosotros mismos, los otros y el resto del mundo".

A esta situación se le ha sumado una estrategia institucional que cuenta con el apoyo del área de psiquiatría y psicología, estamos llamados a trabajar interprofesionalmente para que las personas que prestan servicios de salud sientan apoyo psicológico para el cuidado de sí mismos y de los demás. Quizás mi misión es apoyar a mis compañeros, escucharlos recíprocamente y recordarles que son también humanos de carne y hueso, de sentimientos y sueños, de esperanza y paciencia, y permitir que expresen sus emociones con frases como: "no tengan miedo de pedir ayuda, si la necesitan la institución tiene cómo ofrecerles ayuda, hablen, no se guarden las cosas porque el desenlace puede ser peor". "Los enfermeros somos más que una línea de atención a la humanidad, somos también humanos".

Desde el inicio de la pandemia han sido ya varios los compañeros que se han contagiado, y créanme es una ola fuerte que llega a orillas de la arena y nos mueve miedos, pesares, sueños, nuestros proyectos en pareja, hijos, familia (...) cuando nos hemos enterado ha sido dificil y más cuando nos enteramos que se encuentran en la Unidad de cuidado Intensivo - UCI- con soporte de ventilación y demás andamiaje para sobrevivir, afortunadamente se han venido recuperando (...) y es una esperanza que vuelve a nuestra alma, pero en lo personal, cuando ocurrió la primera muerte de un trabajador de salud llegué (...) sentí un mar de emociones, pero tipo tsunami (...) donde reinó al llegar a mi casa la desmotivación, el miedo, sentirme triste, pensativo; después compartí esos sentimientos con otros de mis compañeros y los sentimientos fueron muchos tsunamis simultáneos (...).

En este mar inmenso, en silencio, de incertidumbre aun hoy cuando la vacuna está presente, nos preguntamos la humanidad (...) ¿hacia dónde vamos?, ¿Por qué existimos?, ¿Qué mensajes nos deja esta pandemia, para la vida humana sobre su existir?. Creo que las respuestas aún no están a la mano, pero sí puedo decir que "lo humano es vital ante cualquier pandemia, catástrofe o quizás también un tsunami", reconocer lo que somos, lo que sentimos, es también parte de hacer visible las voces de nuestra sociedad, nuestra mente y nuestro quehacer en el cuidado de los seres humanos.

Al realizar un contraste de las vivencias en la atención de la pandemia por COVID 19, se encontró similitud con la investigación de Sun y colaboradores al describir 4 momentos por los que el personal de la enfermería pasó durante la atención de estos pacientes. El primero descrito como aquellas emociones negativas asociadas al miedo, a la infección y la preocupación por los pacientes, el cual se puede comparar con las experiencias vividas y manifestadas como resultado de un primer contacto con un posible caso; el segundo momento denominado estilos de afrontamiento y autocuidado, en donde el personal desarrolló ciertas capacidades de adaptación al transcurrir el tiempo, aprendían de sus experiencias, se cuidaban mejor y desarrollaban mecanismos de afrontamiento para hacer más eficiente la atención de los pacientes por COVID 19 (17).

La tercera etapa fue llamada crecimiento bajo presión, asociado a sentimientos de afecto y agradecimiento, en donde los enfermeros asumieron su trabajo con responsabilidad e identidad personal; esto permitió que también lograran hacer reflexiones personales de lo 
importante de la vida y del rol desempeñado. El último momento denominado emociones positivas, contrastado con el inicio en donde los pensamientos y los sentimientos eran en su mayoría negativos, fueron simultáneamente progresando a emociones y sentimientos positivos, asociados a las medidas adoptadas para el manejo de la pandemia (17). Desde mis vivencias y las de mis compañeros en el contexto clínico colombiano, puedo decir que el proceso fue muy similar, en cuanto a los sentimientos, el afrontamiento y la autorreflexión, que permitieron transformar mi concepto de salud y persona en un entorno de cuidado y autocuidado, que apoyó mi propio crecimiento en ese momento y que permanece en la actualidad. Los miedos se fueron mitigando entre los equipos de trabajo, quienes contaron con el apoyo constante de la institución de salud, mediante el suministro de elementos de protección personal; estos factores fueron claves en las vivencias y sentimientos que se experimentaron en un momento difícil de la humanidad con la pandemia por COVID-19.

\section{Análisis reflexivo desde la Narrativa}

Para el análisis de esta narrativa de la enfermería se va a realizar desde la perspectiva de los cuatro conceptos metaparadigmáticos planteados por Jaqueline Fawcett: persona, ambiente, salud y enfermería (18).

Persona: Como persona frente a esta situación al igual que los demás compañeros también tengo miedo y mi mayor temor es llevar la infección a casa; sin embargo, esta sensación de una u otra forma ayuda a que me cuide más. Por otra parte, además de ser una persona con proyectos y miedos como cualquiera, también soy profesional de la enfermería con un rol administrativo y con personas que pueden acudir a mí para hacer preguntas, expresar sus sentimientos, así como los problemas que implican el vivir en una pandemia y al ser trabajador de la salud en un hospital de alta complejidad, donde se va a dar tratamiento a pacientes con COVID-19, es un gran reto. Por tanto, dependiendo de la respuesta y las herramientas que apoyen al personal y la ayuda de otros profesionales, se puede disminuir el miedo y fortalecer la confianza para actuar cuando llegue el momento, tal como lo afirmo: "...quiero transmitir con respeto y conciencia el sentir de mis compañeros de trabajo".

Ambiente: Estas crónicas se desarrollan en un hospital universitario de Colombia, en donde las personas a las que estamos cuidando han tenido muchas necesidades derivadas del temor por la situación, pero la mayoría de ellos coincidió en que lo que les generaba más temor era llevar la infección a sus hogares. Es por eso que en la institución en los últimos días de febrero de
2020, cuando se veía que era inminente la llegada del virus al país, se empezaron a escribir documentos que permitieran estandarizar la atención de los pacientes. En consecuencia se creó un espacio para realizar exclusivamente el triage de los sintomáticos respiratorios, se realizó el cierre de uno de los servicios de hospitalización para la atención de los pacientes, se hizo un flujograma de atención y se socializó en la primera semana de marzo, cuando se detectó el primer caso de COVID-19 en Colombia. Esta actividad se realizó con todo el personal de enfermería, permitiendo que expresaran sus pensamientos y dudas. Como resultado se generó más confianza en el personal, al percibir que la institución tenía los recursos suficientes para atender a los pacientes positivos.

Después de esta intervención inicial, se efectuó un paso a paso para el uso de los elementos de protección personal; es decir, cómo debían colocárselos y cómo retirarlos. También se crearon tres kits de atención: uno para los profesionales de salud que debían realizar los procedimientos generadores de aerosoles, otro para las personas que iban a trasladar a los pacientes a diferentes áreas de la institución y un tercero para quienes estarían en contacto todo el tiempo con los pacientes. Una semana después como parte de las intervenciones educativas adicionales se comenzaron a realizar simulacros de cómo pronar a los pacientes, una estrategia que ya se había aplicado en el continente Asiático y Europeo que podría mejorar la evolución clínica de estos pacientes; al respecto se realizaron simulaciones con el mayor número de profesionales, con especial énfasis en aquellos que se encontraban en las áreas de urgencias, UCI y cuidados intermedios, dando la oportunidad a quienes tenían dudas para que las pudieran aclarar y así generar confianza en el personal. Después de esta capacitación se escucharon comentarios positivos, los que permitieron comprender que el personal se mostraba más tranquilo para atender los pacientes, tal como se demostró en un trabajo de investigación que se realizó en New York (19).

Con respecto al momento de atender al primer paciente, teniendo en cuenta los procedimientos que se habían llevado a cabo, unos profesionales de la salud estaban con miedo, otros tranquilos pero se avanzó con la atención y se cometieron errores; afortunadamente cuando salió la prueba que fue negativa, dio la posibilidad de mejorar y seguir haciendo simulaciones de traslado, reanimación e intubación. Por otra parte, los profesionales de la enfermería con su grupo de trabajo aprovecharon para realizar la simulación de cómo ponerse los elementos de protección personal y como retirarlos, ya que según sus experiencias en otros países eran los momentos donde se podían contagiar. Después 
de pasar una semana, nuevamente se practicó la socialización con el personal de enfermería, presentando algunos cambios en los procedimientos, lo que motivó que algunos dijeran "otra vez cambiaron las cosas"; al respecto se les explicó desde el principio que era una situación cambiante y que por tanto debían estar atentos a las nuevas directrices.

Para las primeras semanas de abril fue necesario abrir un servicio adicional de hospitalización, hablé con la enfermera que estaría liderando este servicio, así como a cuidar a los pacientes que ingresaran, le pregunté cómo se sentía y me manifestó "mi miedo es infectar a mi familia, hasta mi mamá me dijo que debía dejar de trabajar, pero yo le dije que no", yo le comenté "Vas a estar bien, tienes los conocimientos, la institución nos está dando los elementos de protección personal, lo importante es que cuando termines el turno te bañes". Ha trascurrido el tiempo y hasta el presente ha aumentado la confianza del personal en la atención y cuidado de los pacientes con COVID-19. Se debe agregar que con el apoyo de las universidades se han formado algunos profesionales sobre la forma de atender a pacientes con esta infección; así han transcurrido los días y se sigue dando lo mejor para estar en "primera línea". No obstante, a veces pareciera que ya se normalizó la pandemia, hay días buenos y otros no tanto, sobre todo cuando se contagia uno de nuestros compañeros o alguno de nuestros familiares. Lo más importante es que se cumplen las normas relacionadas con la higiene de las manos con agua y jabón, mantener el distanciamiento social y desinfectar el entorno de trabajo, para así "cuidar a nuestros pacientes".

Definitivamente, no ha sido fácil el manejo administrativo de la situación, fue necesario hacer cambios en los turnos del personal, asumir nuevas conductas, pero como lo mencionó la encargada de la estrategia multimodal de higiene de manos "el lado positivo de la pandemia es que para el mes de abril se logró una adherencia de más del 95\% en la higiene de manos"; sin duda la adherencia a esta práctica y a otras de autocuidado se han aumentado y la mayoría de personas están comprometidas. Se debe destacar que del personal que ha atendido a los pacientes con COVID-19, hasta el momento son pocos los contagiados; esta situación ha permitido que se aprenda de lo desconocido, así genere miedo ya que se está en la capacidad de asumir retos y seguir cuidando a los pacientes con calidad y humanización en tiempo difíciles.

Conviene subrayar, que también esta es la oportunidad para recordarle a las organizaciones de salud que tienen un deber moral con su cliente interno en cuanto a educar, orientar y escuchar sus necesidades de mane- ra holística; por tanto, se deben generar estrategias de abordaje presenciales y virtuales del proceso de autocuidado y cuidado de los otros, para atender a las personas con condiciones mínimas de bioseguridad, salud mental, entornos saludables y procesos que hagan énfasis en el uso de la comunicación asertiva entre la gestión estratégica, la táctica y operativa (20).

Salud: Según Fawcett el concepto hace referencia al proceso de vivir y morir. El coronavirus está envuelto en un genoma de ARN monocatenario de sentido positivo de una sola hebra de aproximadamente 26 a $32 \mathrm{~Kb}$, una de las longitudes más extensas conocidas para este tipo de virus y un tamaño de 80 a $220 \mathrm{~nm}$ de diámetro (21). Frente a las características biológicas y químicas que posee el virus hace a los humanos más vulnerables en procesos sociales de interacción que ponen en riesgo la salud de las personas. Además, el coronavirus se transmite por vía respiratoria, al hablar, estornudar, toser, mediante contacto directo o mediado por objetos que estén contaminados. El mayor riesgo lo tienen los profesionales de la salud cuando realizan algún procedimiento que sea generador de aerosoles (22). En este sentido la salud física, mental y espiritual se ha visto afectada por las medidas de confinamiento y las dinámicas de atención en los centros asistenciales.

Por otra parte, se ha observado en pacientes hospitalizados que al inicio de la infección por COVID-19, presentan síntomas asociados con una neumonía viral, como: fiebre, tos, dolor de garganta, mialgias, fatiga y otros síntomas menos comunes que incluyen cefalea, mareos, dolor abdominal, náuseas y vomito $(23,24)$. Hay que mencionar que algunos factores como la edad avanzada y la presencia de comorbilidades como enfermedades pulmonares crónicas, asma, afecciones cardiacas crónicas, diabetes, obesidad mórbida, enfermedad renal crónica son los responsables del desenlace fatal de esta infección en algunos de los pacientes $(24,25)$.

Se ha descrito que el $81 \%$ de las personas infectadas desarrollan una enfermedad de leve a moderada en la que no se desarrolla una neumonía viral; el 14\% tiene una enfermedad grave que se caracteriza por signos y síntomas como disnea, taquipnea, saturación de oxígeno en sangre y existe un $5 \%$ de casos que alcanzan un estado crítico, que incluye el desarrollo del síndrome de dificultad respiratoria aguda, arritmias y shock séptico (26). De igual manera la neumonía causada por el coronavirus se evidencia por una distribución bilateral de condensaciones irregulares y opacidad en vidrio esmerilado en la Tomografía Axial Computarizada (TAC) (23). Por tanto, los pacientes que alcanzan el estado crítico requieren el ingreso a la UCI para manejo del shock con inotrópicos, ventilación mecánica, adminis- 
tración de antibióticos y otros procedimientos especializados, como diálisis y la oxigenación por membrana extracorpórea (ECMO). Las características particulares que muestran algunos marcadores de falla multiorgánica presentan cambios en el laboratorio como: linfopenia, enzimas hepáticas elevadas, elevación de lactato deshidrogenasa (LDH), marcadores inflamatorios elevados (Proteína C reactiva [PCR], ferritina), Dímero D elevado, procalcitonina elevada, tiempos prolongados de protrombina (PT), troponina elevada, y Creatina fosfoquinasa elevada (CPK) (27). También, la evidencia sugiere que la infección puede desencadenar la sobreproducción de citoquinas en algunos pacientes, conocida como tormenta de citoquinas, que se asocia con una mayor probabilidad de un desenlace fatal (26).

En cuanto al proceso de vida y muerte a causa de esta pandemia en mis compañeros de trabajo, tuvo un gran impacto la muerte de uno de ellos; ese día hubo desesperanza, tristeza y llanto que nos recordó lo que estábamos viviendo. Muchos compañeros se infectaron, afortunadamente sin un desenlace fatal, ellos manifestaron los angustiosos momentos que vivieron, los que terminaron hospitalizados y en cuidados intensivos, con la angustia por sentir que no podían respirar; otros que no requirieron hospitalización, sin embargo, experimentaron una angustia similar por haber infectado a sus familiares, con la consecuencia de que algunos de ellos sí fallecieron; factores que tuvieron efectos psicológicos y emocionales con sentido de culpa. Esto ha sido documentado y se ha demostrado que más del 50 $\%$ de una muestra de 1210 personas presentaron un impacto psicológico que se clasificó de moderado a grave, asociado más al sexo femenino, fenómeno que se agrava puesto que la mayoría del personal de enfermería son mujeres y además deben cumplir otros roles como los de madres y cuidadoras. (28). Li y colaboradores realizaron una encuesta a diferentes profesionales de la salud en donde se determinó la presencia de síntomas depresivos $(50,4 \%)$, ansiosos $(44,6 \%)$, insomnio $(34,0 \%)$ y reacción al estrés $(71,5 \%)(5,28)$. Los datos anteriores permiten evidenciar el gran impacto en la salud física y emocional de las personas de primera línea, especialmente en las mujeres y en el personal de la enfermería.

Desde mi vivencia personal, a pesar de sentir temor y el estar en muchos momentos con personas positivas para COVID-19, no me infecté. No obstante, al escuchar a mis compañeros contar sus angustias, estas se trasmitían y causaban en mí sentimientos de tristeza, ansiedad y angustia, especialmente cuando estos compañeros quedaron con secuelas como hipertensión arterial, cefalea constante, tos, vértigo, entre otros.
La fisiopatología de la infección ha hecho que los sistemas de salud colapsen, que el mundo se encuentre en una carrera por encontrar una vacuna y poder acceder a ella, más cuando las potencias mundiales han comprado millones y millones de dosis, lo que dificulta a los países del tercer mundo acceder a este mecanismo de contención. Esto ha tenido un impacto en la salud pública, que se traduce en observar a familias enteras con secuelas mentales por la cuarentena, la ansiedad por que se les administre la vacuna, otros por expandir una información falsa para que la población no se vacune, la muerte de alguno de los seres queridos o la pérdida del trabajo. A lo enumerado anteriormente se suman los problemas que se han presentado en la salud mental de los trabajadores de salud. Al respecto, el gobierno no ha intervenido oportunamente para evitar todas las secuelas emocionales de la pandemia. Sin embargo, desde la enfermería se ha venido trabajando y avanzando por brindar una atención segura, humanizada y con prácticas de autocuidado para que la "primera línea" siga en pie de lucha contra un virus desconocido y que ha causado un cambio total en la sociedad.

Enfermería: A través de esta profesión se promueve la oportunidad para demostrar el liderazgo de la enfermería en tiempos difíciles. Se ha tratado de hacer lo mejor a pesar de las circunstancias. En mi condición de jefe escucho a las personas, trato de trasmitir sus inquietudes, de resolver sus dudas e inquietudes; es decir, que éste ha sido mi rol ante la adversidad. Se sabe que esta situación no ha sido fácil para muchos profesionales de la enfermería en Colombia y en el mundo; se ha experimentado miedo, estrés, agotamiento por los turnos extensos, acompañados de un sin número de elementos de protección personal que aumentan el cansancio. No obstante, estos factores adversos no han detenido el liderazgo de la enfermería y se han podido implementar algunas estrategias para mejorar el cuidado de los pacientes, tales como la organización de las áreas, tener una persona dedicada a verificar el correcto uso de los elementos de protección personal, crear estrategias para que el equipo de enfermería tenga que ingresar la menor cantidad de veces a la habitación, sin disminuir la calidad en la atención(16,29,30). Personalmente en algunos momentos tampoco ha sido fácil, pero siempre aliento a mis compañeros a seguir adelante con entusiasmo y optimismo en todo lo que concierne con nuestra vida profesional.

Quizás mi misión es apoyar a mis compañeros, escucharlos recíprocamente y recordarles que son también humanos, de carne y hueso, de sentimientos y sueños, de esperanza y paciencia, y permitir que expresen sus emociones con frases como: "no tengan miedo de pedir ayuda si la necesitan, la in- 
Scientific Journal of Nursing

stitución tiene como ofrecerles ayuda, hablen, no se guarden las cosas porque el desenlace puede ser peor"

De igual modo se ha podido aplicar el proceso de atención de enfermería (PAE) en los pacientes afectados por el COVID-19, con resultados positivos por parte de los colegas que han utilizado esta metodología. Desde mi rol como administrativo debo hacerle seguimiento a esta actividad y encontrar diagnósticos de enfermería como "Deterioro de la ventilación espontanea", "Patrón respiratorio ineficaz" (31) (Ver Tabla 1), esto ha sido clave para mejorar la atención y lograr un cuidado de enfermería sistemático.

Tabla 1: Diagnósticos de enfermería más implementados en la pandemia por COVID-19

\begin{tabular}{|c|c|}
\hline $\begin{array}{c}\text { Diagnóstico de enfermería } \\
\text { NANDA }\end{array}$ & Intervenciones y Metas de enfermería \\
\hline $\begin{array}{l}\text { “Deterioro de la ventilación } \\
\text { espontanea”, (31) }\end{array}$ & $\begin{array}{l}\text { "mejorar la oxigenación del paciente a través de un tiempo de } \\
96 \text { horas", "elevar cabecera de cama a } 30^{\circ} \text { o } 45^{\circ} \text { con el fin de } \\
\text { permitir el descenso diafragmático" } \\
\text { "educar al paciente sobre la importancia de mantenerse el } \\
\text { mayor tiempo posible en posición prono para mejorar satura- } \\
\text { ción" } \\
\text { "apoyo de actividades dependientes, interdependiente e inde- } \\
\text { pendientes para lograrlo" }\end{array}$ \\
\hline $\begin{array}{l}\text { "Patrón respiratorio ineficaz" } \\
\text { (31) }\end{array}$ & $\begin{array}{l}\text { "identificar signos de dificultad (polipnea o desaturación, } \\
\text { uso de músculos de accesorios, cianosis bucal) e informar } \\
\text { oportunamente, monitorización continúa de signos vitales en } \\
\text { especial frecuencia respiratoria, SaO2" }\end{array}$ \\
\hline
\end{tabular}

Fuente: Basado en los Diagnósticos Enfermeros: Definiciones y clasificación 2018-2020. NANDA-I. Autores 2021

Una vez que se diseñó el PAE y se plasmó en la historia clínica, el auxiliar de enfermería ejecuta las actividades propuestas y al día siguiente se realiza una evaluación como la siguiente: "Se realiza evolución del plan de cuidados de enfermería, paciente con soporte de oxigeno por cánula nasal a 2 litros con SaO2 de 88\%, paciente manifiesta sensación de ahogo, tensión arterial dentro de los límites normales y frecuencia cardiaca con tendencia a la taquicardia, se insiste al paciente en la importancia de mantenerse en posición prono con el fin de mejorar la oxigenación, paciente febril, se continua con las actividades de enfermería planeadas"; así se da continuidad al cuidado hasta el cumplimiento de la meta o de ser necesario, se realiza un nuevo plan de cuidado si la condición clínica del paciente ha cambiado.

Es necesario indicar, que estas situaciones generalmente muestran lo mejor de los profesionales de la enfermería, quienes se han comprometido con las actividades, participando activamente para mejorar y prestar la mejor atención y con calidad a los pacientes (15); muchos se sienten más seguros estando en el área de COVID-19, que en otras áreas de la institución, desarrollando estrategias empíricas que contribuyen con la atención de los pacientes; igualmente, han generado buena comunicación en su equipo de trabajo y con los de las otras jornadas. Como se ha podido observar, estas prácticas mejoran los procesos de cuidado en circunstancias desconocidas. No obstante falta mucho por aprender, aunque se ha demostrado la importancia de los equipos de la enfermería en la atención de los pacientes; también hace falta que algunas directivas de las instituciones de salud o gubernamentales reconozcan y empoderen a los grupos de la enfermería para que se pueda transformar la práctica.

\section{Conclusiones}

- Este trabajo permitió compartir algunas vivencias de los profesionales y auxiliares de la enfermería en relación al abordaje de la pandemia tales como sus sentimientos, emociones y vivencias, que los llevó a transitar de momentos de angustia a un proceso de trasformación, en el que a pesar de continuar con ese miedo, lideraron la atención de los pacientes con COVID-19 y permitieron que muchas personas pudieran regresar a casa.

- Es importante resaltar que las instituciones de salud y las gubernamentales se deben preocupar por la salud física, emocional, mental y espiritual de sus trabajadores en el campo de la enfermería, tal como 
se mencionó y se evidenció en este relato y en las otras investigaciones realizadas. Conviene subrayar, que las secuelas físicas y psicológicas que se han derivado de ésta pandemia en los trabajadores de la salud no han sido documentadas del todo y pueden afectar su vida laboral.

- Para el mundo a pesar de los avances científicos, la globalización y las nuevas tecnologías ha sido difícil entender el comportamiento de esta pandemia; por su parte los gobernantes han realizado lo que creen que ha sido conveniente, de acuerdo a los pronósticos epidemiológicos y a las opiniones de sus asesores, unos han acertado y otros han fracasado. Lo mismo ha sucedido con la sociedad y con las instituciones de salud, que han realizado acciones para el manejo de la situación que han sido adecuadas, pero al final se está aprendiendo "es nuestra primera pandemia", lo importante es que se debe avanzar en el autoconocimiento y reconocer los aspectos positivos y negativos que fueron el desenlace de las decisiones que se tomaron.

- Como sociedad esta situación nos debe enseñar a valorar lo que es importante y como profesionales de la salud tenemos grandes retos para seguir aportando a partir del cuidado en la enfermería, así como empoderarnos con el apoyo de las instituciones de salud y en los ámbitos de la salud pública.

\section{Conflicto de intereses}

Los autores declaran no tener ningún conflicto de interés

\section{Referencias Bibliográficas}

1. Wu F, Zhao S, Yu B, Chen YM, Wang W, Song ZG, et al. A new coronavirus associated with human respiratory disease in China. Nature. 2020;(579) 265-269. DOI: https://doi.org/10.1038/s41586-020-2008-3

2. Jin Y, Yang H, Ji W, Wu W, Chen S, Zhang W, et al. Virology, Epidemiology, Pathogenesis, and Control of COVID-19. Viruses. 2020;12(4):372. DOI: https://doi.org/10.3390/v12040372

3. University Johns Hopkins. Coronavirus COVID-19 (2019-nCoV) [Internet]. Baltimore; 2021 [Consultado el 6 de febrero de 2021]. Disponible en: https://coronavirus.jhu.edu/map.html.

4. Instituto Nacional de Salud. Coronavirus en Colombia [Internet]. Bogota; 2021. [Consultado el 6 de febrero de 2021]. Disponible en: https://www.ins.gov.co/Noticias/Paginas/Coronavirus.aspx.

5. Lai J, Ma S, Wang Y, Cai Z, Hu J, Wei N, et al, et al. Factors Associated With Mental Health Outcomes Among Health Care Workers Exposed to Coronavirus Disease 2019. JAMA Netw open. 2020:e203976. DOI: https://doi.org/10.1001/jamanetworkopen.2020.3976

6. Gaitán A. Review Essay: Exploring Alternative Forms of Writing Ethnography. Forum Qual Sozialforsch / Forum Qual Soc Res. 2000;1(3). https://doi.org/10.17169/FQS-1.3.1062

7. Ellis E, Adams T, Bochner A. View of Autoethnography: An Overview . Forum Qual Sozialforschung-FQS. 2011;12(1).

8. Bochner AP, Ellis C. Personal Narrative as a Social Approach to Interpersonal Communication. Commun. Theory, 1992 2(2) 165-172.

9. Couser GT. Recovering bodies : illness, disability, and life-writing. University of Wisconsin Press; 1997.

10. Denzin N. Interpretive Biography. Newbury Park, CA:sage; 1989.

11. Zaner R. Conversations on the edge : narratives of ethics and illness. Washington, DC: Georgetown University Press; 2004.

12. Blanco M. Autoetnografía: una forma narrativa de generación de conocimientos. Andamios . 2012;9:49-

74.

13. Ngunjiri F, Hernandez K, Chang H. View of Living Autoethnography: Connecting Life and Research | Journal of Research Practice. J Res Pract. 2010;6(1).

14. Hernández JR. Manual de Autobservación. (Asociación Canaria para el Desarrollo de la Salud a través 
de la Atención, ed.). [Internet]. España; 2018.Disponible en: https://www.laatencionalpresente.com/wp-content/ uploads/2018/07/Manual-de-Autobservacion-2018.pdf

15. Fernandez R, Lord H, Halcomb E, Moxham L, Middleton R, Alananzeh I, et al. Implications for COVID-19: A systematic review of nurses' experiences of working in acute care hospital settings during a respiratory pandemic. Int J Nurs Stud. 2020;111:103637. DOI: https://doi.org/10.1016/j.ijnurstu.2020.103637

16. Liu Q, Luo D, Haase JE, Guo Q, Wang XQ, Liu S, et al. The experiences of health-care providers during the COVID-19 crisis in China: a qualitative study. Lancet Glob Heal. 2020; 8(6):e790-e798. DOI: hhttps://doi. org/10.1016/S2214-109X(20)30204-7

17. Sun N, Wei L, Shi S, Jiao D, Song R, Ma L, et al. A qualitative study on the psychological experience of caregivers of COVID-19 patients. Am J Infect Control. 2020;48(6):592-598. https://doi.org/10.1016/j. ajic.2020.03.018

18. Fawcett, J. "The metaparadigm of nursing: International in scope and substance". En K. Krause y P. Astedt-Kurki (Eds.), International perspectives on nursing: A joing effort to explore nursing internationally, Finland, Tampere University, Department of Nursing, 1992.

19. Yuriditsky E, Horowitz JM, Nair S, Kaufman BS. Simulation-based uptraining improves provider comfort in the management of critically ill patients with COVID-19. J Crit Care. 2021;61:14-17. DOI: https://doi. org/10.1016/j.jcrc.2020.09.035

20. Balderas M. Administración de los servicios de enfermería . Séptima edición. (McGraw-Hill, ed.).; 2015.

21. Su S, Wong G, Shi W, Liu J, Lai ACK, Zhou J, et al. Epidemiology, Genetic Recombination, and Pathogenesis of Coronaviruses. Trends Microbiol. 2016;24(6):490-502. DOI: https://doi.org/10.1016/j.tim.2016.03.003

22. Zhang W, Du RH, Li B, Zheng XS, Yang XL, Hu B, et al. Molecular and serological investigation of 2019nCoV infected patients: implication of multiple shedding routes. Emerg Microbes Infect. 2020; 9(1): 386-389. DOI: https://doi.org/10.1080/22221751.2020.1729071

23. Harapan H, Itoh N, Yufika A, Winardi W, Keam S, Te H, et al. Coronavirus disease 2019 (COVID-19): A literature review. J Infect Public Health. 2020; 13(5):667-673. DOI:https://doi.org/10.1016/j.jiph.2020.03.019

24. Krishnan A, Hamilton JP, Alqahtani SA, A.Woreta T. A narrative review of coronavirus disease 2019 (COVID-19): clinical, epidemiological characteristics, and systemic manifestations. Intern Emerg Med.2021:116. https://doi.org/10.1007/s11739-020-02616-5

25. Lai CC, Liu YH, Wang CY, Wang YH, Hsueh SC, Yen MY, et al. Asymptomatic carrier state, acute respiratory disease, and pneumonia due to severe acute respiratory syndrome coronavirus 2 (SARS-CoV-2): Facts and myths. J Microbiol Immunol Infect. 2020; 53(3):404-412. DOI: https://doi.org/10.1016/j.jmii.2020.02.012

26. Da Silva SJ, Silva CT, Guarines KM, Mendes RP, Pardee K, Kohl A, et al. Clinical and Laboratory Diagnosis of SARS-CoV-2, the Virus Causing COVID-19. ACS Infect Dis. 2020; 6(9):2319-2336. DOI: https://doi. org/10.1021/acsinfecdis.0c00274

27. Terpos E, Ntanasis-Stathopoulos I, Elalamy I, Kastritis E, Sergentanis TN, Politou M, et al. Hematological findings and complications of COVID-19. Am J Hematol. 2020; 95(7):834-847. DOI: https://doi.org/10.1002/ ajh.25829

28. . Huarcaya-Victoria J. Consideraciones sobre la salud mental en la pandemia de COVID-19. Rev Peru Med Exp Salud Publica. 2020;37(2):327-334. https://doi.org/10.17843/RPMESP.2020.372.5419

29. Newby JC, Mabry MC, Carlisle BA, Olson DW, Lane BE. Reflections on nursing ingenuity during the COVID-19 pandemic. J Neurosci Nurs. 2020; 52(5):E13-E16. DOI: https://doi.org/10.1097/JNN.0000000000000525

30. Liu YE, Zhai ZC, Han YH, Liu YL, Liu FP, Hu DY. Experiences of front-line nurses combating coronavirus disease-2019 in China: A qualitative analysis. Public Health Nurs. 2020; 37(5):757-763. DOI: https://doi. org/10.1111/phn.12768

31. Herdman T, Kamitsuru S. Diagnósticos Enfermeros: Definiciones y clasificación 2018-2020. NANDA-I. Undécima ed. España: Elsevier. 2019. 